\title{
Comparative study of intra vaginal misoprostol (PGE1) with intracervical dinoprostone (PGE2) gel for induction of labour
}

\author{
Bina M. Raval, Nainesh S. Zalavadiya*, Pushpa A. Yadava, Shital T. Mehta
}

Department of Obstetrics and Gynecology, Vadilal Sarabhai General Hospital Ahmedabad, Gujarat, India

Received: 10 July 2018

Accepted: 02 August 2018

\section{*Correspondence:}

Dr. Nainesh S. Zalavadiya,

E-mail: naineshzalavadiya@gmail.com

Copyright: () the author(s), publisher and licensee Medip Academy. This is an open-access article distributed under the terms of the Creative Commons Attribution Non-Commercial License, which permits unrestricted non-commercial use, distribution, and reproduction in any medium, provided the original work is properly cited.

\begin{abstract}
Background: Labour is a final consequence of Pregnancy and is inevitable. The timing of labour may vary widely but it will happen sooner or later. The aim of the present research was to study the safety, efficacy and effect of intra vaginal Misoprostol and intra cervical Dinoprostone gel for induction of labour.

Methods: 100 patients who required labour of induction were included in this prospective cross-sectional study from September 2017- March 2018. 50 patients of them received $25 \mathrm{mcg}$ tablet misoprostol intravaginal and 50 patients of them required $0.5 \mathrm{mg}$ intracervical dinoprostone gel and doses were repeated every 6 hourly for up to maximum 6 doses for Misoprostol and 3 doses for Dinoprostone gel.

Results: The majority of patients had gestational age above 40 weeks and between $37-40$ weeks in PGE2 and PGE1 group respectively. The mean time taken for the onset of labour was less in Misoprostol than in Dinoprostone group (43.22 min v/s $1 \mathrm{hr} 40 \mathrm{~min})$. The mean time taken for induction to active phase of labour $(1 \mathrm{hr} 42 \mathrm{~min} \mathrm{v} / \mathrm{s} 4 \mathrm{hr} 10 \mathrm{~min})$ and active phase to delivery ( $3 \mathrm{hr} 6 \mathrm{~min} \mathrm{v} / \mathrm{s} 4 \mathrm{hr} 54 \mathrm{~min}$ ) was less in Misoprostol than Dinoprostone group. The mean time required for induction to delivery was less in Misoprostol group ( $5 \mathrm{hr} 2 \mathrm{~min} \mathrm{v} / \mathrm{s} 11 \mathrm{hrs}$ ). Requirement of oxytocin for augmentation of labour was almost equal in both groups. Caesarean section rate was less in Misoprostol group $(10 \% \mathrm{v} / \mathrm{s} 22 \%)$. Maternal side effects were minimal in either groups and neonatal outcome was good in both the groups.

Conclusions: Both Misoprostol and Dinoprostone gel are safe, effective for cervical ripening and induction but Misoprostol is more cost effective and stable at room temperature.
\end{abstract}

Keywords: Dinoprostone, Induction of labour, Misoprostol

\section{INTRODUCTION}

Labour is a final consequence of Pregnancy and is inevitable. The timing of labour may vary widely but it will happen sooner or later. In some $5-25 \%$ of pregnancies, there comes a time when the fetus and/or mother would be better off if delivery was conducted.

Induction of labour implies the artificial initiation of uterine contractions after period of viability for purpose of vaginal delivery whereas augmentation of labour is a process of stimulation of uterine contraction that were already present but found to be inadequate. Induction of labour is indicated when continuation of pregnancy risks the life of mother or fetus. The baby should be delivered in a good condition, in an acceptable time frame and with minimum maternal discomfort and least side effects. The induction of labour is common practice in obstetrics. ${ }^{1-3}$

Prostaglandins alter the extracellular ground substances of cervix, ripens the cervix and also increase the activity of collagenase in the cervix. They also allow for an 
increase in intracellular calcium levels, causing contraction of myometrial muscle. Currently two prostaglandins analogues are available for the purpose of cervical ripening - Misoprostol and Dinoprostone gel., ${ }^{4,5}$

Misoprostol (15-deoxy-16-hydroxy-16methyl-PGE1) was the first synthetic prostaglandin analogue to be made available for treatment of peptic ulcer. Impressed by its stimulation actions on the uterus, Ramos S et al in 1993 used it for the management of several obstetrics conditions. Misoprostol is available as 25, 50, 100, 200 microgram tablets.

Dinoprostone (PGE2) was a synthetic preparation of naturally occurring prostaglandin E2. PGE2 gel was available in $2.5 \mathrm{ml}$ syringe for intracervical application of $0.5 \mathrm{mg}$ of Dinoprostone. ${ }^{6}$

The methods of administration that has been well known is endocervical Dinoprostone. Though this is widely used, the disadvantage is that it is expensive and required refrigeration for storage and bring it to room temperature before use. Misoprostol is comparably cheap, safe and effective vaginally administered Prostaglandins, which claims to have limited side effects available with the name Misoprostol or PGE1. It does not need any refrigeration.

\section{METHODS}

100 patients admitted for induction of labour in V.S.G.H. were randomly selected for study. It was a prospective cross-sectional comparative study.

\section{Indications for Induction in present study}

Postdate, IUGR, PIH, Preeclampsia, Eclampsia, Mild Polyhydramnios (maximum vertical pocket $\geq 8 \mathrm{~cm}$ and $<12 \mathrm{~cm}$ ), Mild Oligohydramnios (maximum vertical pocket $\geq 1 \mathrm{~cm}$ and $\leq 2 \mathrm{~cm}$ ).

\section{Inclusion criteria}

- Singleton pregnancy, Indication for induction of labour

- Cephalic presentation

- >37weeks completed gestation confirmed by Ultrasonography

\section{Exclusion criteria}

- Previous LSCS or any uterine surgery

- Mal presentation

- Contracted pelvis or Cephalo-Pelvic disproportion

- Antepartum haemorrhage

- Unsatisfactory CTG

- Active Genital herpes

- Pelvis tumors

- Bronchial asthma.

\section{Method of Induction}

1. After informed consent had been obtained, 50 patients with an indication for labour induction received with $0.5 \mathrm{mg}$ intra-cervical Dinoprostone gel and 50 patients received $25 \mathrm{mcg}$ tablet Misoprostol in posterior fornices of vagina. Doses were repeated 6hourly up to maximum 6 times for Misoprostol and 3 times for Dinoprostone gel according to progress of labour.

2. After drug insertion, patients were monitored for signs of labour, maternal vital signs, fetal heart rate and progress of labour. The fetal heart rate was monitored by either intermittent auscultation or continuous fetal heart rate monitoring. A partogram was strictly maintained in all patients.

3. Oxytocin was started depending on the modified bishop's score and in the absence of adequate uterine contractions after 6 hours of the last dose, and or for augmentation of the labour in the arrest of labour. Oxytocin was started the dose of 5units in $500 \mathrm{ml} \mathrm{RL}$ in primigravida and 2.5 units in $500 \mathrm{ml} \mathrm{RL}$ in multigravida and titrated accordingly.

4. Membranes were ruptured, when the cervix was completely effaced with cervical dilatation of more than $3 \mathrm{cms}$ or at onset of active stage of labour.

5. The data collection included indication of induction, maternal age, parity, gestational age, induction to onset, onset to active phase of labour, active phase to delivery time, oxytocin augmentation, type of delivery, indication of LSCS, side effects, maternal and neonatal outcomes.

\section{RESULTS}

Total number of patients studied was 100. 50 patients were induced with $25 \mathrm{mcg}$ intra vaginal misoprostol tablet and repeated every 6 hourly up to 6 doses and 50 patients were induced with $0.5 \mathrm{mg}$ intracervical Dinoprostone gel and repeated every 6hourly up to 3 doses.

When gestational age was compared it was seen that there was more number of patients between 37 to 40 weeks $(76 \%)$ in Misoprostol group and numbers of patients with gestational age more than 40 weeks $(36 \%)$ in Dinoprostone group.

Primi gravida formed the largest group in study being $62 \%$ in misoprostol and $56 \%$ in Dinoprostone group. Multigravidas in Misoprostol and Dinoprostone group were $38 \%$ and $44 \%$ respectively.

Table 1: Distribution of cases by gestational age between study groups.

\begin{tabular}{|lll|}
$\begin{array}{l}\text { Gestational } \\
\text { age (weeks) }\end{array}$ & Misoprostol & Dinoprostone \\
\hline $37-40$ & $38(76 \%)$ & $32(64 \%)$ \\
\hline $40.1-42$ & $12(24 \%)$ & $18(36 \%)$ \\
\hline
\end{tabular}


Table 2: Distribution of cases by parity between study groups.

\begin{tabular}{|lll|}
\hline Parity & Misoprostol & Dinoprostone \\
\hline Primi & $31(62 \%)$ & $28(56 \%)$ \\
\hline Multi & $19(38 \%)$ & $22(44 \%)$ \\
\hline
\end{tabular}

The mean time taken for onset of labour was significantly less $(\mathrm{P}=0.0069)$ in Misoprostol group (43.22min v/s 1 hr40min in Dinoprostone group). The Misoprostol leads to early labour and thus early delivery as compared to the Dinoprostone gel.

In Misoprostol group the time taken for induction to active phase ( $1 \mathrm{hr} 42 \mathrm{~min}$ vs $4 \mathrm{hr} 10 \mathrm{~min})$ was less which was statistically significant as $\mathrm{P}=0.006$. Similarly, active phase to delivery interval ( $3 \mathrm{hr} 06 \mathrm{~min} \mathrm{v} / \mathrm{s} 4 \mathrm{hr} 54 \mathrm{~min}$ ) was also less and was statistically significant with $\mathrm{P}=0.01$. Overall there was less induction to delivery interval $95 \mathrm{hr}$ $2 \mathrm{~min}$ vs $11 \mathrm{hr} 12 \mathrm{~min}$ ) and this was statistically significant.

Table 3: Mean time taken for onset of labour.

\begin{tabular}{|lllllll|} 
& Misoprostol & Dinoprostone & $\begin{array}{l}\text { Mean } \\
\text { difference }\end{array}$ & SD (mean) & $\begin{array}{l}\text { Standard } \\
\text { error (mean) }\end{array}$ & P value \\
\hline In all patients & $43.22 \mathrm{~min}$ & $1 \mathrm{hr} 40 \mathrm{~min}$ & $56.78 \mathrm{~min}$ & $77.8 \mathrm{~min}$ & 11.12 & 0.00069 \\
\hline Primigaravida & $44.37 \mathrm{~min}$ & $1 \mathrm{hr} 26 \mathrm{~min}$ & $41.63 \mathrm{~min}$ & $61.69 \mathrm{~min}$ & $19.0 \mathrm{~min}$ & 0.21983 \\
\hline Multigravida & $43.25 \mathrm{~min}$ & $1 \mathrm{hr} 35.67 \mathrm{~min}$ & $52.42 \mathrm{~min}$ & $82.23 \mathrm{~min}$ & $13.96 \mathrm{~min}$ & 0.00527 \\
\hline
\end{tabular}

Table 4: Induction-delivery intervals.

\begin{tabular}{|c|c|c|c|c|c|c|}
\hline & Misoprostol & Dinoprostone & $\begin{array}{l}\text { Mean } \\
\text { difference }\end{array}$ & SD (mean) & $\begin{array}{l}\text { Standard } \\
\text { error (mean) }\end{array}$ & P value \\
\hline Induction to active phase & $1 \mathrm{hr} 42 \mathrm{~min}$ & $4 \mathrm{hr} 10 \mathrm{~min}$ & $2 \mathrm{hr} 28 \mathrm{~min}$ & 161.76 & 24.61 & 0.006 \\
\hline Active phase to delivery & $3 \mathrm{hr} 06 \mathrm{~min}$ & $4 \mathrm{hr} 54 \mathrm{~min}$ & $1 \mathrm{hr} 48 \mathrm{~min}$ & 147.10 & 22.33 & 0.01275 \\
\hline Induction to delivery & $5 \mathrm{hr} 2 \mathrm{~min}$ & $11 \mathrm{hr} 12 \mathrm{~min}$ & $6 \mathrm{hr} 10 \mathrm{~min}$ & 377.60 & 54.97 & 0.0004 \\
\hline
\end{tabular}

Table 5: Indication for induction.

\begin{tabular}{|lll|}
\hline Indication & Misoprostol & Dinoprostone \\
\hline Postdate & $12(24 \%)$ & $18(36 \%)$ \\
\hline IUGR & $10(20 \%)$ & $8(12 \%)$ \\
$\begin{array}{l}\text { PIH } \\
\text { Preeclampsia }\end{array}$ & $16(32 \%)$ & $12(20 \%)$ \\
\hline Eclampsia & $1(2 \%)$ & $3(6 \%)$ \\
\hline Mild Polyhydramnios & $1(2 \%)$ & $1(2 \%)$ \\
$\begin{array}{l}\text { Mild } \\
\text { Oligohydramnios }\end{array}$ & $10(20 \%)$ & $8(16 \%)$ \\
\hline
\end{tabular}

Most common indication for induction of labour in Misoprostol group was PIH and Preeclampsia followed by Postdate $\left(2^{\text {nd }} M / C\right)$ while in Dinoprostone group most common indication of induction was Postdate followed by PIH and Preeclampsia ( $\left.2^{\text {nd }} M / C\right)$.

Table 6: Oxytocin augmentation.

\begin{tabular}{|lll|}
\hline $\begin{array}{l}\text { Oxytocin } \\
\text { augmentation }\end{array}$ & Misoprostol & Dinoprostone \\
\hline Yes & $11(22 \%)$ & \% of patients \\
\hline No & $39(78 \%)$ & $38(76 \%)$ \\
\hline
\end{tabular}

Oxytocin augmentation was required in $22 \%$ patients in Misoprostol group and $24 \%$ patients in Dinoprostone gel group. Need of oxytocin augmentation was almost equal in both study groups.

$90 \%$ of patients in Misoprostol group delivered normally as compared to $78 \%$ patients delivered in Dinoprostone gel group. Less rate of Caesarean section was seen in Misoprostol group.

Table 7: Mode of delivery.

\begin{tabular}{|lll|}
\hline Type of delivery & Misoprostol & Dinoprostone \\
\hline ND & $45(90 \%)$ & $39(78 \%)$ \\
\hline Caesarean & $5(10 \%)$ & $11(22 \%)$ \\
\hline
\end{tabular}

Only one patient in Misoprostol group had failure of induction whereas in Dinoprostone gel group 7 patients had induction failure. The main indication of Caesarean section in Misoprostol group was meconium stained liquor and Dinoprostone gel group was induction failure. Meconium stained liquor was the second most common indication of caesarean section in Dinoprostone group after induction failure.

Table 8: Indication of caesarean section.

\begin{tabular}{|lll|}
\hline Indication & Misoprostol & Dinoprostone \\
\hline Fetal distress & $1 \%(20 \%)$ & $1 \%(9.09 \%)$ \\
\hline Induction failure & $1 \%(20 \%)$ & $7 \%(63.63 \%)$ \\
\hline $\begin{array}{l}\text { Meconium stained } \\
\text { liquor }\end{array}$ & $3 \%(60 \%)$ & $3 \%(27.27 \%)$ \\
\hline
\end{tabular}


Although maternal complication like fever with chills, hyperstimulations (Hypersystole and tachysystole) and Meconium stained liquor were more in misoprostol group than dinoprostone group. Significant side effects were not seen.

Table 9: Side effects.

\begin{tabular}{|lll|}
\hline Side effects & $\begin{array}{l}\% \text { of patients } \\
\text { Misoprostol }\end{array}$ & $\begin{array}{l}\% \text { of patients } \\
\text { Dinoprostone }\end{array}$ \\
\hline Nausea, vomiting & $8 \%$ & $4 \%$ \\
\hline Fever with chills & $16 \%$ & - \\
\hline Diarrhoea & $6 \%$ & $4 \%$ \\
\hline $\begin{array}{l}\text { Hyperstimulation } \\
\text { Meconium stained }\end{array}$ & $8 \%$ & - \\
\hline \begin{tabular}{l} 
liquor \\
\hline
\end{tabular} & $12 \%$ & $6 \%$ \\
\hline
\end{tabular}

4 babies were admitted in NICU delivered in Misoprostol group and 6 babies were admitted in NICU delivered in Dinoprostone group. There was no significant difference between two study groups regarding NICU admissions.

Table 10: Comparison NICU admissions (days).

\begin{tabular}{|ll|l|}
\hline $\begin{array}{l}\text { NICU admissions } \\
\text { (days) }\end{array}$ & Misoprostol & Dinoprostone \\
\hline <7days & 3 & 4 \\
\hline >7days & 1 & 2 \\
\hline
\end{tabular}

Out of 4 babies admitted in NICU in Misoprostol group two babies (50\% of admission) were admitted due to meconium aspiration syndrome. Similarly, out of 6 babies admitted in NICU in Dinoprostone group three babies (50\% of admissions) were admitted due to meconium aspiration syndrome. There was no significant difference between both study groups regarding indications of admissions in NICU.

Table 11: Indication for NICU admissions.

\begin{tabular}{|lll|}
\hline Birth asphyxia & Misoprostol & Dinoprostol \\
\hline Low birth weight & $1(25 \%)$ & $1(16.6 \%)$ \\
\hline $\begin{array}{l}\text { Meconium aspiration } \\
\text { syndrome }\end{array}$ & $2(50 \%)$ & $1(16.6 \%)$ \\
\hline RDS & $0(0 \%)$ & $1(50 \%)$ \\
\hline
\end{tabular}

\section{DISCUSSION}

The introduction of prostaglandins to clinical practice, particularly their local use for cervical ripening, has decreased major difficulties of major induction. Duration between induction and delivery has been decreased dramatically by introduction of prostaglandins. Similarly, it also decreased associated complications of amnionitis and fetal infection. The baseline data of our study population including maternal age, gravidity and gestational age were comparable with similar studies. ${ }^{1-3}$
The mean time taken for onset of labour was less in misoprostol group (43.22min v/s $1 \mathrm{hr} 40 \mathrm{~min}$ ) (Table 3). There was no significant difference between the primigravida and the multigravida in both the groups regarding the time taken for onset of labour (Table 3 ).

In this study the mean induction to delivery interval was less in misoprostol group ( $5 \mathrm{hr} 02 \mathrm{~min} \mathrm{v} / \mathrm{s} 11 \mathrm{hrs} 12 \mathrm{~min}$ ), which was statistically significant $(\mathrm{P}=0.001)$. Similar results were seen in study in 2003 by Agarwal et 7 where it was $(12.8 \pm 6.4 \mathrm{hrs} \mathrm{v} / \mathrm{s} 18.53 \pm 8.5 \mathrm{hrs})$ and in study in 2017 by Yadav $\mathrm{S}$ et al $(5.39 \pm 2.97 \mathrm{hrs}$ vs $10.88 \pm 7.33 \mathrm{hrs}$ respectively). ${ }^{8}$ In 2003 Garry D et al and in 2014 Liu A et al, also concluded in his study that interval between from start of induction to vaginal delivery was significantly shorter in Misoprostol group. ${ }^{9,10}$ Thus Misoprostol reduces the mean duration of labour (Table 4) which reduces the duration of suffering of a patient in labour and also provides fast delivery.

In present study, indication for induction in Misoprostol group were post date pregnancy in $24 \%$ and $\mathrm{PIH}$ and preeclampsiain $32 \%$ whereas in Dinoprostone group $36 \%$ and $20 \%$ respectively induced for postdate and PIH and Preeclampsia (Table 5). Thus, majority of induction was due to these two conditions.

In present study oxytocin augmentation required in 11 patients in Misoprostol group (22\%) and in 12 patients in Dinoprostone group (24\%) (Table 6). In study by Herabutya et al, oxytocin augmentation required in $35 \%$ and $34 \%$ patients in Misoprostol group and Dinoprostone group respectively. ${ }^{11}$

The present study showed that Misoprostol was able to increase the vaginal deliveries $(90 \%)$ compared to Dinoprostone group (Misoprostol group had decrease rate of caesarean section rate $(10 \%)$ compared to Dinoprostone (22\%) (Table 7).

In the present study, in the Misoprostol group, out of 5 patients who underwent caesarean section only one (1) was for failure of induction whereas in Dinoprostone group 7 out of 11 patients were operated for caserean section due to failure of induction which was consistent with study by Patil $\mathrm{K}$ et al and Bhaskar $\mathrm{M}$ et al. ${ }^{2,3}$ In the Misoprostol group 3 out of 5 underwent Caesarean section due to meconium stained liquor. Though total 3 patients had meconium stained liquor out of 5 patients in comparison to 3 patients had meconium stained liquor out of 11 patients underwent for caesarean section in Dinoprostone group. Thus, meconium stained liquor was seen more in Misoprostol group (Table 8).

Maternal side effects were minimal in both the groups. In Misoprostol group, $16 \%$ patients had fever with chills, $8 \%$ had nausea and vomiting and $6 \%$ had diarrhoea, $8 \%$ had hyperstimulations (Table 9). 
Hypertonus was defined as one contraction with a duration of $>2 \mathrm{~min}$, Tachysystole as $>6$ contractions in 10 min for two consecutive 10 min periods.

Uterine hyperstimulation is when either of these condition (hypertonus v/s tachysystole) leads to a non reassuring fetal heart rate pattern. Because of the frequency of tachysystole with vaginal administration of Misoprostol, some researchers are studying oral and sublingual/buccal routes to determine if effectiveness can be maintained while decreasing the incidence of tachysystole.

The neonatal outcomes in both the groups were similar. Mundle and Younge evaluated the effect of Misoprostol for labour induction on neonatal admission. ${ }^{12}$ They found that neonatal outcome was similar in both groups, cord blood acid base analysis did not differ between both the groups. Also, in present study no significant difference found between two group in NICU admissions and majority of admissions were due to meconium aspiration syndrome (Table 10 and 11).

The mean overall induction cost in Misoprostol group was much less in contrast to Dinoprostone group. As Misoprostol does not need refrigeration, its affordability as well as its availability in the peripheral areas is more than the Dinoprostone gel which requires refrigeration.

\section{CONCLUSION}

Present study results revealed that, Misoprostol is better inducing agent as compared to the Dinoprostone gel because it has short induction to delivery intervals and thus short duration of labour and advantage of rapid labour as required in pre-eclampsia and eclampsia. Misoprostol group had more numbers of normal vaginal delivery as compared to Dinoprostone gel group. Thus, Misoprostol reduces the Caesarean section rate and also had less chances of failure of induction.

In Misoprostol group the most common indication of caserean section was Meconium stained liquor and in Dinoprostone group the most common indication for caserean section was Induction failure. Although Hyperstimulation and Meconium stained Liquor was more in Misoprostol group in few patients and did not had any effect on the neonatal admission. In both studies group the main indication for NICU admission was Meconium aspiration syndrome. Misoprostol also does not need cold chain storage and is cheaper. Thus, Misoprostol can be considered as safe, efficacious, cheap and mother and fetus friendly drug for the induction of labour.

Funding: No funding sources

Conflict of interest: None declared
Ethical approval: The study was approved by the Institutional Ethics Committee

\section{REFERENCES}

1. Sahu L, Chakravertty B. Comparison of prostaglandin E 1(misoprostol) with prostaglandin E 2 (dinoprostone) for labor induction. $\mathbf{J}$ Obstet Gynecol India. 2004;54:139-42.

2. Patil KP, Swamy MK, Rao RK. Oral misoprostol vs intra-cervical dinoprostone for cervical ripening and labour induction. J Obstet Gynecol India. 2005;55(2):128-31.

3. Murthy BK, Arkalgud MS. Misoprostol alone versus a combination of Dinoprostone and Oxytocin for induction of labour. $\mathrm{J}$ Obstet Gynec India. 2006;56(5):413-6.

4. Witter FR. Prostaglandin E2 preparations for preinduction cervical ripening. Clin Obstetr Gynecol. 2000 Sep 1;43(3):469-74.

5. Arias F. Pharmacology of oxytocin and prostaglandins. Clin Obstet Gynecol. 2000;43(3):455-68.

6. American College of Obstetricians and Gynecologist. New U.S. food and drug administration labelling on Cytotec (Misoprostol) use and pregnancy. Committee opinion Washington. DC: ACOG. 1999;28.

7. Agarwal N, Gupta A, Kriplani A, Bhatla N. Six hourly vaginal misoprostol versus intracervical dinoprostone for cervical ripening and labor induction. J Obstetr Gynaecol Res. 2003 Jun 1;29(3):147-51.

8. Yadav S, Chandwaskar N. Comparative study of misoprostol sublingually and dinoprostone gel intracervically for cervical ripening and induction of labor. Int J Reprod Contracept Obstet Gynecol. 2017 Jul 26;6(8):3624-7.

9. Garry D, Figueroa R, Kalish RB, Catalano CJ, Maulik D. Randomized controlled trial of vaginal misoprostol versus dinoprostone vaginal insert for labor induction. $\mathbf{J}$ Maternal-Fetal Neonatal Med. 2003 Jan 1;13(4):254-9.

10. Liu A, Lv J, Hu Y, Lang J, Ma L, Chen W. Efficacy and safety of intravaginal misoprostol versus intracervical dinoprostone for labor induction at term: A systematic review and meta-analysis. J Obstetr Gynaecol Res. 2014 Apr 1;40(4):897-906.

11. Herabutya Y, O-Prasertsawat P, Pokpirom J. A comparison of intravaginal misoprostol and intracervical prostaglandin E2 gel for ripening of unfavorable cervix and labor induction. J Obstetr Gynaecol Res. 1997 Aug;23(4):369-74.

12. Windrim R, Bennett K, Mundle W, Young DC. Oral administration of misoprostol for labor induction: a randomized controlled trial. Obstetr Gynecol. 1997 Mar 1;89(3):392-7.

Cite this article as: Raval BM, Zalavadiya NS, Yadava PA, Mehta ST. Comparative study of intra vaginal misoprostol (PGE1) with intracervical dinoprostone (PGE2) gel for induction of labour. Int J Reprod Contracept Obstet Gynecol 2018;7:376973. 